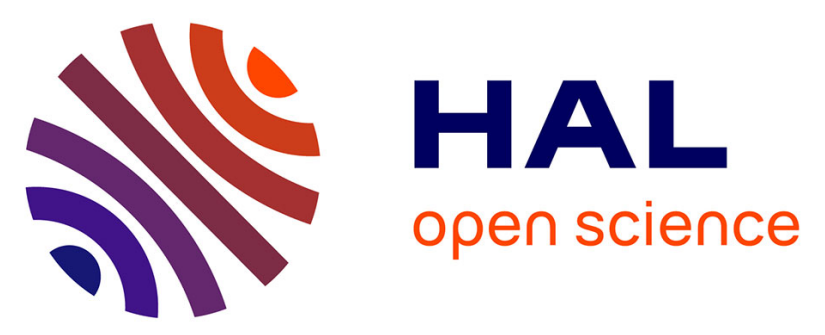

\title{
Receptor for Advanced Glycation end products (RAGE) modulates neutrophil adhesion and migration on Glycoxidated extracellular matrix
}

Fatouma Touré, Jean Marie Zahm, Roselyne Garnotel, Elise Lambert, Noel Bonnet, Ann Marie Schmidt, Fabien Vitry, Jacques Chanard, Philippe Gillery, Philippe Rieu

\section{To cite this version:}

Fatouma Touré, Jean Marie Zahm, Roselyne Garnotel, Elise Lambert, Noel Bonnet, et al.. Receptor for Advanced Glycation end products (RAGE) modulates neutrophil adhesion and migration on Glycoxidated extracellular matrix. Biochemical Journal, 2008, 416 (2), pp.255-261. 10.1042/BJ20080054 . hal-00478948

\section{HAL Id: hal-00478948 https://hal.science/hal-00478948}

Submitted on 30 Apr 2010

HAL is a multi-disciplinary open access archive for the deposit and dissemination of scientific research documents, whether they are published or not. The documents may come from teaching and research institutions in France or abroad, or from public or private research centers.
L'archive ouverte pluridisciplinaire HAL, est destinée au dépôt et à la diffusion de documents scientifiques de niveau recherche, publiés ou non, émanant des établissements d'enseignement et de recherche français ou étrangers, des laboratoires publics ou privés. 
Receptor for Advanced Glycation end products (RAGE) modulates neutrophil adhesion and migration on Glycoxidated extracellular matrix

Fatouma Touré * ${ }^{\dagger} \mathrm{MD}$, Jean-Marie $\mathrm{Zahm}{ }^{\ddagger} \mathrm{PhD}$, Roselyne Garnotel* $\mathrm{PhD}$,

Elise Lambert ${ }^{\star} \mathrm{PhD}$, Noel Bonnet ${ }^{\ddagger} \mathrm{PhD}$, Ann Marie Schmidt ${ }^{\S} \mathrm{MD} \mathrm{PhD}$, Fabien Vitry, MD **

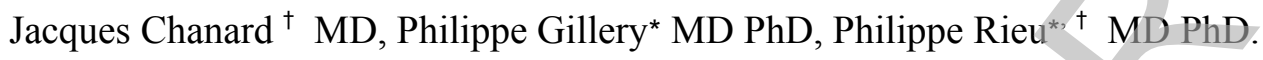

${ }^{*}$ CNRS UMR6198, ${ }^{\dagger}$ Division of Nephrology, ${ }^{\ddagger}$ INSERM U514 and ** Clinical Research Unit Reims, France. ${ }^{\S}$ Columbia University College of Physicians and Surgeons, New York, USA.

Running title: RAGE modulates PMN migration on AGE-collagen

Address correspondence to: $\quad$ Philippe Rieu, M.D., Ph.D.

Division of Nephrology and CNRS UMR6198

Hôpital Maison Blanche,

45 rue Cognacq-Jay -51092 Reims

France.

Fax: 0326788482

Phone: 0326784331

E-mail: prieu@chu-reims.fr

F. Touré is supported by a fellowship from "Société de Néphrologie". 


\section{ABSTRACT}

Introduction: Advanced glycation end products (AGEs) accumulate in collagen molecules during uremia and diabetes, two diseases associated with high susceptibility to bacterial infection. Because neutrophils bind to collagen during their locomotion in extravascular tissue toward the infected area, we investigated whether glycoxidation of collagen (AGE-collagen) alters neutrophil migration. Experimental design: Type I collagen extracted from rat tail tendons was used for in vitro glycoxidation (AGE-collagen). Neutrophils were obtained from peripheral blood of healthy adults volunteers and used for in vitro study of adhesion and migration on AGE- or control Collagen. Results: Glycoxidation of collagen increased adhesion of neutrophils to collagen surfaces. Neutrophil adhesion to AGE-collagen was inhibited by rabbit anti-RAGE antibody and by PI3-Kinase inhibitors. No effect was observed with MAPK/ERK and MAPK/P38 inhibitors. AGE-collagen was able to: $1 /$ induce PI3-Kinase activation in neutrophils and 2/ inhibit chemotaxis and chemokinesis of chemoattractant-stimulated neutrophils. Finally, we found that blocking RAGE with antiRAGE antibodies or inhibiting PI3-kinase with PI3-Kinase inhibitors restored f-MLP-induced neutrophil migration on AGE-collagen. Discussion: These results show that RAGE and PI3Kinase modulate adhesion and migration rate of neutrophils on AGE-Collagen. Modulation of adhesiveness may account for the change in neutrophil migration rate on AGE-collagen. Since neutrophils rely on their ability to move to perform their function as the first line of defense against bacterial invasion, glycoxidation of collagen may participate in the suppression of normal host defense in diabetic and uremic patients.

\section{Abbreviations : $\mathrm{f}-\mathrm{MLP}=\mathrm{N}$-formyl-Met-Leu-Phe}




\section{INTRODUCTION}

Diabetic and uremic patients have an increased susceptibility to bacterial infection, suggesting that professional phagocytes such as neutrophils are functionally impaired $[1,2]$. However, the function of neutrophils isolated from these patients and tested in vitro is not greatly defective. Thus, it is conceivable that the in vivo environment plays a major role in the dysfunction of neutrophils.

Diabetes and chronic uremia are characterized by the accelerated generation of advanced glycation ends products (AGEs) [3, 4]. AGEs are formed on proteins and peptides by non-enzymatic glycoxidation [5, 6]. Glucose, a carbonyl compound present at millimolar concentrations in blood, reacts non-enzymatically with amino groups of proteins to form a Schiff-base, which undergoes the Amadori rearrangement. A complex series of poorly understood oxidative reactions converts the Amadori product to various AGEs. Glycoxidation products may induce protein cross-linking, affect protein function and interact with cell surface receptors such as RAGE [7]. AGE accumulation seems to contribute to the pathophysiology of uremic and diabetic complications $[8,9]$. Because AGEs are irreversible chemical modifications of proteins, they accumulate with time in long lived proteins such as collagen. The half-life of skin collagen, for example, has been calculated to be 15 years [10]. Collagen proteins are therefore a major source for AGE accumulation. Several studies have demonstrated high concentrations of the glycoxidation products $\mathrm{N}^{\varepsilon}$ (carboxymethyl)lysine and pentosidine in collagen (AGE-collagen) from uremic and diabetic patients $[3,11]$.

Neutrophils rely on their ability to move to perform their function as the first line of defense against bacterial invasion. In response to inflammatory signals, neutrophils quickly leave the blood stream by crossing vascular endothelium and progress across the extravascular space towards the infected area through regulated and reversible interactions of 
cell adhesion molecules with extracellular matrix components [12]. During migration, neutrophils undergo various modifications which enable them to respond in an adapted way to sequential stimuli and which prime them for their final mission, i.e. the killing of infectious microorganisms. Neutrophils bind to collagen, a major component of the extacellular matrix, during their locomotion in extravascular tissue. Adhesion molecules of the $\beta 2$ and $\beta 1$ integrin families have been shown to mediate neutrophil interaction with collagen [13, 14].

Because collagen is glycoxidated during uremia and diabetes, two diseases associated with high susceptibility to bacterial infection and because neutrophil functions have been shown to be modulated by AGE-modified protein [15-22], we investigated whether AGEcollagen alters neutrophil migration. 


\section{EXPERIMENTAL DESIGN \& METHODS}

\section{Preparation of AGE-collagen:}

Type I collagen extracted from rat tail tendons, as previously described [13], was used for in vitro glycoxidation. Incubation with D-glucose, $1 \mathrm{M}$ (in phosphate buffer $50 \mathrm{mM}, \mathrm{pH} 7.4$ ), was made under sterile conditions. Control collagen was subjected to the same conditions except that D-glucose was omitted. After ten days incubation, preparations were extensively dialyzed against PBS and acetic acid (18mM) until complete solubilization, lyophilized, and conserved at $-80^{\circ} \mathrm{C}$. Presence of AGEs was determined using spectrofluorimetry. Briefly, control-collagen and AGE-collagen $(2 \mathrm{mg} / \mathrm{ml})$ were dissolved in acetic acid solution $(18 \mathrm{mM})$.

As fluorescence is a property of AGEs, samples were submitted to spectrofluorimetry (excitation 340/ emission 415) as previously described [18]. Mean fluorescence was $212.25 \pm$ 82.46 units for control collagen and $604.51 \pm 57.5$ units for AGE-collagen $(p \leq 0.05)$. Preparations were tested for presence of LPS; they contained less than $0.5 \mathrm{EU} / \mathrm{ml}$ of endotoxin (Limulus Test, Bio-Whittaker, Walkersville, Maryland).

\section{Isolation of human neutrophils}

Peripheral blood was obtained from healthy adults volunteers by venipuncture into $0.1 \mathrm{ml}$ of EDTA anticoagulant. Neutrophils were prepared as described [23] by centrifugation on polymorphprep (Nycomed, Oslo, Norway) and suspended at $5 \times 10^{6}$ cells $/ \mathrm{ml}$ in HBSS solution without calcium and without magnesium (Gibco, Paisley, Scotland). All procedures were performed with endotoxin-free solutions and all experiments were completed within $3 \mathrm{~h}$ of blood collection. When indicated, cells were first pre-incubated with buffer alone, various inhibitors or antibodies: Wortmanin (10nM), LY294002 $(50 \mu \mathrm{M})$, PD98059 $(40 \mu \mathrm{M})$, SB203580 $(10 \mu \mathrm{M})$, rabbit anti-human RAGE antibody $(70 \mu \mathrm{g} / \mathrm{ml})$, and irrelevant rabbit antibody $(70 \mu \mathrm{g} / \mathrm{ml}$, Dakocytomation, Denmark) for $30 \mathrm{~min}$ at room temperature. Inhibitors were purchased from Sigma Chemical Co, St Louis, MO. Wortmanin and SB203580 optimal 
concentrations were determined accordingly to previous publications $[24,25]$ A dose response curve was performed to detect the optimal dose of PD98059 : partial inhibition was detected at $10 \mu \mathrm{M}$ and complete inhibition at $40 \mu \mathrm{M}$. The latter concentration was then employed in all the experiments. When indicated (Fab')2 fragments of the immune $\operatorname{Ig} G$ to RAGE or non immune control IgG were used. (Fab')2 fragments were prepared by pepsin digestion, and optimal concentrations were determined as previously described [19].

\section{Adhesion assays}

Strong adhesion (spreading) of neutrophils to Control collagen or AGE-collagen was tested. 96-wells plates were coated overnight with $250 \mu \mathrm{g} / \mathrm{ml}$ of control collagen or AGE-collagen. Neutrophils, $4 \times 10^{6}$ cells $/ \mathrm{ml}$, were suspended in Dulbeco modified medium with calcium and magnesium (Gibco, Paisley Scotland). When indicated, cells were first preincubated with kinase inhibitors, anti-RAGE antibody or buffer alone during $15 \mathrm{~min}$ at room temperature. $\mathrm{f}$ $\operatorname{MLP}\left(10^{-8} \mathrm{M}\right)$ or vehicle alone was then added just prior incubation at $37^{\circ} \mathrm{C}$ for 30 minutes. After the indicated time, wells were washed with binding buffer. Cells that remained attached to the well were fixed with glutaraldehyde $1 \%$ before nuclear coloration with crystal violet (10\%), for 20 minutes at room temperature. After extensive washing, residual coloration (reflecting the number of adherent cells) was dissolved in acetic acid $(0.5 \mathrm{M})$ and optic density was measured at $560 \mathrm{~nm}$.

\section{In vitro kinase assay}

Ten million neutrophils per well were placed in 6 well plates pre-coated with control collagen or AGE-collagen, and allowed to adhere for $30 \mathrm{~min}$ at $37^{\circ} \mathrm{C}$. Then, medium was discarded and cells were subjected to lysis, at $4^{\circ} \mathrm{C}$, in buffer containing : Tris $10 \mathrm{mM}, \mathrm{NaCl} 150 \mathrm{mM}$, EDTA $5 \mathrm{mM}$, Glycerol 10\%, Azide $0.02 \%$, Brij $10 \%$, orthovanadate $0.1 \mathrm{M}$ and protease inhibitors (Sigma Chemical Co, St Louis, MO). Immunoprecipitation of PI3-kinase from lysates was done using Phospho-Tyrosine Monoclonal Antibody (P-Tyr-100, New England 
Biolabs, Beverly, MA). The precipitate, containing PI3-Kinase, was used for in vitro formation of radio-labelled Phosphatidil-Inositol-Phosphate (PIP) in the presence of micella (Phosphatidil-Inositol and phosphatidil-serine), ATP $(2.5 \mu \mathrm{M})$ and $\gamma \mathrm{P}^{32}$. The reaction was performed at $37^{\circ} \mathrm{C}$ for $15 \mathrm{~min}$ and stopped by addition of $100 \mu \mathrm{HCL} 1 \mathrm{~N}$ and $350 \mu \mathrm{l}$ of chloroform/Methanol (1/1), followed by centrifugation $2 \mathrm{~min}$ at $3000 \mathrm{~g}$. After 2 successive washes with $200 \mu 1 \mathrm{Methanol} / \mathrm{HCl}(1: 1), 110 \mu 1$ were taken from the lower phase of each tube corresponding to the radio-labelled PIP formed in vitro. This sample was then submitted to chromatography on a silica plaque. Radioactivity was revealed by autoradiography of the silica plaque.

\section{Morphological examination of neutrophils}

Neutrophils were allowed to adhere for 30 minutes at $37^{\circ} \mathrm{C}$, to coverslip chambers coated with control collagen or AGE-collagen (with or without stimulation with f-MLP, $10^{-8} \mathrm{M}$ ). Cells were then fixed with $4 \%$ paraformaldehyde ( 15 minutes, RT), and permeabilized with $0.05 \%$ triton for 1 minute, before staining with fluorescein phalloidin $(0.33 \mu \mathrm{M}, 45 \mathrm{~min}, \mathrm{RT}$, Molecular Probes, Eugene, Oregon). Images of each condition were acquired on an inverted fluorescent microscope. Cellular area, a measure of cell spreading, was determined by manually tracing the cell perimeter in the digital image. Determinations were made for 20 cells for each condition.

\section{Under Agarose Assay}

Petri-dishes were coated overnight with control collagen or AGE-collagen $(250 \mu \mathrm{g} / \mathrm{ml})$. Agarose (indubiose, $2 \%$ ) was boiled in endotoxin-free sterile saline solution, followed by 1:1 dilution with a solution containing : MEM (Gibco, Paisley Scotland), filtered plasma, penicillin and streptomycine, to achieve a final agarose concentration of $1 \%$ that was then distributed in precoated petri-dishes. Using a plastic template and a beveled punch, three 2-mm wells were created each separated by a distance of $0.5 \mathrm{~cm}$. The central well received $8 \mu 1$ of prepared 
neutrophils at concentration of $40 \times 10^{6}$ cells $/ \mathrm{ml}$. Eight microliters of opsonized zymosan (SigmaAldrich, St.Louis, MO) was placed in the upper left well as a chemoattractant and $8 \mu$ lof MEM alone in the lower right well (negative control). Dishes were incubated 2.5 hours at $37^{\circ} \mathrm{C}$ with $5 \% \mathrm{CO}_{2}$ and then fixed with formalin for 10 minutes. After removal of agarose, dishes were stained with May-Grunwald-Giemsa. Migration was measured under the microscope: the distance from the outer edge of the center well to the leading edge of the migratory cells was measured. Both random (chemokinesis, distance toward MEM) and directed (chemotaxis, distance toward Zymosan) migration were measured. Directed migration (response to chemoattractant) was defined as: (migration toward chemoattractant) - (migration toward PBS).

\section{Time-Lapse -video-microscopy}

Neutrophils $(500,000 / \mathrm{ml})$ in DMEM +/+ ( Dulbeco,s Modified Eagles Medium, Calcium and magnesium $+/+$ ) were placed on polystyrene 24 well plates precoated with control collagen or AGE-collagen. Plates were incubated in a temperature controlled chamber $\left(37^{\circ}\right)$ with $\mathrm{CO}_{2} 5$ $\%$ mounted on an inverted microscope (Axiovert, Zeiss). Spontaneous migration and migration in response to $10^{-8} \mathrm{M}$ f-MLP were recorded by acquisition of successive images of the wells (each $20 \mathrm{sec}$ ) over 5 minutes. Images were used for quantification of migration speed using home-made software. This software was developed at the Inserm unit 514 to quantify the speed of migration of cells in $2 \mathrm{D}$ cultures. In the first image, 20 cells were randomly selected and semi-automatic tracking of these cells was performed by indicating each cell in the following images of the serie. When all trajectories have been drawn, cells' rate of migration was then calculated by the software. When indicated, migration was studied after preincubation with inhibitors: Wortmanin or anti-RAGE (Fab)'2.

\section{Statistical analysis}

The amount of cell adhesion, cell surface, and cell migration rates were compared firstly using a Kruskl Wallis test. If a difference was observed a Mann Whitney test was then 
performed for group by group comparison. Statistical significance was defined as $*, p<0.05$, $* *, \mathrm{p}<0.01, * * *, \mathrm{p}<0.001$.

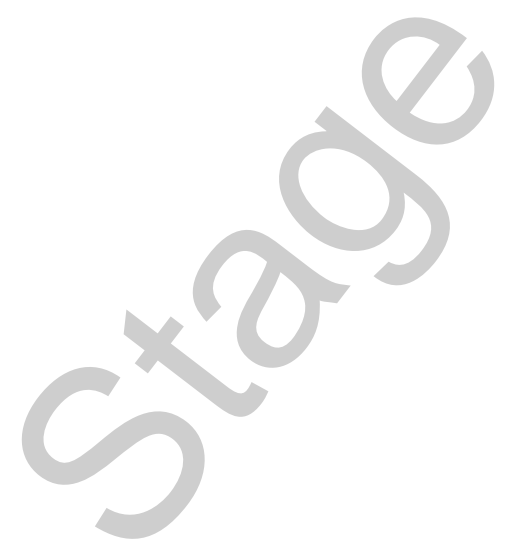




\section{RESULTS}

\section{Adhesion of neutrophils to AGE-collagen is mediated by RAGE and PI3Kinase}

In the initial series of experiments, we examined whether glycoxidation of collagen influences neutrophil adhesion. We found that adhesion of f-MLP-activated neutrophils to AGE-Collagen was increased when compared with control collagen $(\mathrm{p}<0.01)$ (Figure 1). Preincubation of neutrophils with rabbit anti-RAGE antibodies before f-MLP stimulation reduced cell adhesion, suggesting that RAGE was involved in the increased binding of neutrophils to AGE-collagen. We next analysed the role of MAPK/ERK, MAPK/P38 and phosphatidylinositol 3-kinase (PI3-Kinase) in f-MLP-stimulated cell adhesion to AGECollagen. The specific PI3-Kinase inhibitor wortmanin at $10 \mathrm{nM}$, significantly inhibited neutrophil adhesion stimulated by f-MLP. In contrast, no effect was observed with p38 MAPK inhibitor (SB203858) or MAPK/ERK inhibitor (PD98059) (Figure 1).

To determine whether the effect of wortmanin on neutrophil adhesion to AGE collagen was due to f-MLP inhibition, we tested the ability of wortmanin to inhibit neutrophil adhesion to AGE-Collagen in absence of stimulation. Adhesion of resting neutrophils to AGE-collagen was increased compared to adhesion to control collagen (Figure 2). Preincubation of resting neutrophils with rabbit anti-RAGE antibodies or with wortmanin significantly reduced cell adhesion to AGE-Collagen $(\mathrm{p}<0.01)$. Taken together, these results indicate that adhesion of resting neutrophils to AGE-Collagen involves RAGE and PI3Kinase. To confirm induction of the PI3-Kinase signalling pathway, we analyzed the in vitro PIP3 biosynthesis in adherent resting neutrophils on AGE-Collagen and on Control Collagen. As shown in figure 3, PIP3 biosynthesis was increased on AGE-Collagen in comparison with Control Collagen. 


\section{Glycoxidation of collagen modulates migration of f-MLP-stimulated neutrophils on} collagen surface

In response to f-MLP activation, neutrophils were morphologically spread on AGEcollagen while they appeared polarized on control collagen (Figure 4A). Determination of cell surface area confirmed that neutrophil shape, without reaching statistical significance, was more extended on AGE-collagen than on control collagen (Figure 4B). Because glycoxidation of collagen had an effect on neutrophil morphologic polarity, we studied chemotaxis and chemokinesis. Directional migration in response to a chemo-attractant gradient (chemotaxis) was performed using an "under-agarose" neutrophil migration assay. In this system, we found that the distance of neutrophil migration to a distant chemoattractant source was significantly reduced on AGE-collagen $(10.6 \pm 7.8 \mathrm{~mm})$ when compared with control collagen $(34.4 \pm 6.8 \mathrm{~mm}, \mathrm{p} \leq 0.001)$ (Figure 5A). f-MLP-induced random migration (chemokinesis) of neutrophils placed on the collagen coated surface were recorded by timelapse video microscopy. Unstimulated neutrophils had a slightly higher migration rate on AGE-collagen $(6.7 \pm 1.36 \mu \mathrm{m} / \mathrm{min})$ than on control collagen $(5.57 \pm 0.8 \mu \mathrm{m} / \mathrm{min}$, NS) (Figure 5B). In the presence of f-MLP, cell migration rates were significantly increased on control collagen $(5.57 \pm 0.8 \mu \mathrm{m} / \mathrm{min}$ to $11.6 \pm 1.9 \mu \mathrm{m} / \mathrm{min} ; \mathrm{p}<0.001)$ but not on AGE collagen $(6.7 \pm$ $1.36 \mu \mathrm{m} / \mathrm{min}$ to $8.2=0.4 \mu \mathrm{m} / \mathrm{min} ; \mathrm{p}>0.05)$. These findings demonstrate that glycoxidation of collagen surface modulates neutrophil migration. It slightly accelerates migration of resting neutrophils, but mainly blocks chemotaxis and chemokinesis of chemoattractant-stimulated neutrophils. 


\section{RAGE and PI3-Kinase modulate migration of f-MLP-stimulated neutrophils on AGE-}

\section{collagen}

Next we examined whether inhibition of adhesion of neutrophils by anti-RAGE antibodies and PI3-Kinase inhibitors influences migration on AGE-collagen. We found that pretreatment of neutrophils with anti-RAGE (Fab')2 led to a significant increase in neutrophil migration rate after f-MLP stimulation $(9.2 \pm 1.1$ instead of $6.9 \pm 1.2 \mathrm{~mm}$; $\mathrm{p}<0.01)$. Control (Fab')2 had no effect on neutrophil migration on AGE-collagen (Figure 6A). Non-specific stimulation of Beta-2 integrins by the anti-RAGE (Fab')2 was tested and as expected, anti-RAGE (Fab')2 does not modify neutrophil migration on Control Collagen (Figure 6B). Furthermore, we found that preincubation of neutrophils with PI3-Kinase inhibitors (10 nM wortmanin or 50 $\mu \mathrm{M}$ LY294002) caused neutrophil polarization (data not shown) and a marked increase in neutrophil motility on AGE-collagen $(11.8 \pm 1.5$ vs $6.9 \pm 1.2 \mathrm{~mm} ; \mathrm{p}<0.001)$ whereas, no effect was observed on control-collagen (Figure 7). These results show that RAGE and PI3Kinase modulate migration of f-MLP-stimulated neutrophils on AGE-collagen. 


\section{DISCUSSION}

Neutrophils are the first line of defense against infection. They exert bactericidal activity following successive steps including activation, adhesion, migration and phagocytosis. AGE-proteins have been shown to modulate neutrophil production of reactive oxygen species, actin polymerization and phagocytosis $[16,22]$. In the present study, we were interested in modulation of neutrophil adhesion and migration by glycoxidated collagen (AGE-collagen). We showed that AGE-collagen modulates neutrophil function: adhesion is enhanced while chemotactic migration is inhibited. Receptor for Advanced Glycation End products (RAGE) and PI3 Kinase are involved in these processes.

Our results suggest a very close relationship between adhesion and migration. Indeed, the strong adhesion of f-MLP-stimulated neutrophils to AGE-collagen was associated with a lack of migration. Conversely, inhibition of neutrophils adhesion to AGE-collagen coated surface by anti-RAGE antibodies or by PI3-Kinase inhibitors was associated with an increase in migration rate. Cell motion requires adhesion to the substrate. Cell-substratum attachment strength is a central variable governing cell migration speed. If the interaction of the substrate is too weak, the cells cannot gain traction, but if it is too strong, they become stuck. Between these extremes, adhesive interactions of moderate affinity allow migration [26]. Our results show that glycoxidation of collagen enhances the strength of adhesion of neutrophils. We hypothesized that this modulation of adhesion strength leads to modulation of the migration rate. As expected, inhibition of neutrophils' strong adhesion by anti-RAGE antibodies and PI3 Kinase inhibitors restores migration on AGE-collagen. Our results are in agreement with previous reports: studies with Src-family and Syk deficient neutrophils have verified that a defect in integrin-mediated firm adhesion is associated with an increase in f-MLP-induced neutrophil migration [27]. At the opposite, treatment of f-MLP-activated neutrophils with the 
actin polymerizing agent jasplakinolide strengthens neutrophil adhesion to their adhesive surface and considerably reduces their migration rate [28]. These results suggest that neutrophil migration speed depends on the strength of transient cell-substratum attachments. Modulation of adhesiveness may account for the change in neutrophil migration rate on AGECollagen.

Glycoxidation of proteins, leading to accumulation of AGEs is accelerated during uremia and diabetes. These proteins may behave like pro-inflammatory molecules following interaction with their receptors. One of the best characterized receptors, RAGE (receptor for advanced glycation end products), is a multiligand receptor and a member of the immunoglobulin superfamily. Collisson and colleagues have recently described the presence of RAGE on neutrophil membranes [16]. Here we show that RAGE is involved in neutrophil adhesion and migration processes. Glycoxidation of collagen modulates neutrophil migration. Spontaneous migration was slightly increased, whereas chemotactic migration was significantly inhibited. The increase in spontaneous migration on AGE-Collagen was not statistically significant, but taken together these results are in agreement with previous studies showing that AGE-proteins inhibit transendothelial migration of f-MLP-activated neutrophils, while they increase transendothelial migration of unstimulated neutrophils [20]. Similar modulation of monocyte migration has been demonstrated with AGE-modified proteins. AGE-proteins increase migration of resting monocytes $[19,29,30]$ but reduce chemotaxis of f-MLP-activated monocytes by a RAGE-dependant pathway [19]. Our results show that RAGE-dependant modulation of strong adhesion may account for these variations of migration rate.

We-show that PI3-Kinase is also involved in neutrophil adhesion and migration on AGE-Collagen. RAGE signalling is usually mediated by activation of the Mitogen Activated Protein Kinase/ERK but activation of the p38 signalling pathways also has been reported [31- 
34]. Until recently, PI3-Kinase was not a classical signalling pathway involved in RAGE activation. However, Vincent et al. have recently reported a direct activation of the PI3Kinase pathway by RAGE in dorsal root ganglia neurons in response to stimulation with S100/calgranulin [35]. This report shed light on the possible activation of PI3-Kinase by RAGE. Another hypothesis to explain PI3-Kinase activation in neutrophils during adhesion to AGE-collagen could be related to integrin engagement. Neutrophil adhesion to collagen is a multicomponent process including integrin ligation and post-binding events such as cell spreading. Cell spreading allows stronger adhesion. It is a fundamental event in which the contact area with a solid substrate increases because of actin polymerization. During this process, actin dynamics are coupled to activation of PI3-Kinase, an enzyme that is stimulated by clustering of $\beta 1$ and $\beta 2$ integrins [36-38]. One may speculate that RAGE regulates integrin-mediated adhesion to AGE-collagen and that subsequent PI3-Kinase activation induced by integrin engagement reinforces neutrophil adhesion to AGE-collagen.

We tested the effect of PI3-kinase inhibitors on chemokinesis. PI3-kinase inhibition has been shown to partially reduce directed migration (chemotaxis) but not random migration (chemokinesis) of f-MLP-activated neutrophils [39-41]. In agreement with these results, we confirmed that PI3-Kinase inhibition did not affect f-MLP-induced chemokinesis on Control Collagen. However, we found that PI3-kinase inhibition greatly enhanced f-MLP-induced neutrophil chemokinesis on AGE-collagen. These results show that PI3-Kinase activation on AGE-collagen is a key step in the modulation of adhesion and migration. Our results do not allow any conclusion on the mechanism leading to activation of the PI3Kinase pathway. Investigation is underway to establish if the connection between RAGE and PI3-Kinase pathways is direct or secondary to integrins engagement.

Accelerated glycoxidation of collagen has been observed in uremic and diabetic patients $[3,11]$. Our results show that AGE-Collagen modulates neutrophil adhesion and 
migration in vitro. Animal studies are needed to demonstrate that this phenomenon is also true in vivo. Because the directed motion of neutrophils to sites of infection is essential for protection against microbial infections, one may speculate that intensive glycoxidation of collagen is one mechanism that may contribute to the increased incidence of bacterial infections within uremic and diabetic population.

\section{ACKNOWLEDGEMENTS:}

F. Touré is supported by a fellowship from "Société de Néphrologie". 


\section{REFERENCES}

1 Moutshen, M. P., Scheen, A. J. and Lefebvre, P. J. (1992) Impaired immune responses in diabetes mellitus: Analysis of the factors and mechanisms involved. Relevance to the increased susceptibility of diabetic patients to specific infections. Diabetes Metab 18, 187-207.

2 Vanholder, R. and Ringoir, S. (1993) Infectious morbidity and defects of phagocytic function in end-stage renal disease: a review. J Am Soc Nephrol 3, 1541-1554.

3 Sell, D. R. and Monnier, V. M. (1990) Endstage renal disease and diabete Catalyzes the formation of a pentose-drived crosslink in aging human Collagen. J Clin Invest 85

4 Miyata, T., Ueda, Y., Shinzato, T. and al, e. (1996) Accumulation of albumin-linked and free-form pentosidine in the circulation of uremic patients with end-stage renal failure: Renal implications in the pathophysiology of pentosidine. J Am Soc Nephrol 7, 1198-1206.

5 Maillard, L. C. (1912) Action des acides aminés sur les sucres: formation de mélanoïdes par voie méthodique. C.R Acad Sci 154, 66-68.

6 Monnier, V. M. and Cerami, A. (1981) Nonenzymatic browning in vivo: Possible process for aging of long-lived proteins. Science 211, 491-494

7 Schmidt, A. M., Yan, S. D., Yan, S. F. and Stern, D. M. (2001) The multiligand receptor RAGE as a progression factor amplifying immune and imflammatory responses. J Clin Invest 108, 949-955.

8 Brownlee, M., Cerami, A. and Vlassara, H. (1988) Advanced glycosylation end products in tissue and the biochemical basis of diabetic complications. N Engl J Med 318, 1315-1321.

9 Miyata, T., Oda, O. and Inagi, R. (1993) Bêta2-Microglobulin modified with advanced glycation end products is a major component of hemodialysis-associated amyloidosis. J Clin Invest 92, 1243-1252.

10 Verzijl, N., DeGroot, J., Thorpe, S. R., Bank, R. A., Shaw, J. N., Lyons, T. J., Bijlsma, J. W. J., Labefer, F. P. J. G., Baynes, J. W. and Tekoppele, J. M. (2000) Effect of Collagen Turnover on the Accumulation of Advanced Glycation End Products. J Biol Chem 275, 39027-39031.

11 Dyer, D., Dunn, J., Thorpe, S. R. and al, e. (1993) Accumulation of Maillard reaction products in skin collagen in diabetes and aging. J Clin Invest 91, 2463-2469.

12 Witko-Sarsat, V., Rieu, P., Descamps-Latscha, B., Lesavre, P. and HalbwachsMecarelli, L. (2000) Neutrophils: Molecules, Functions and Pathophysiological Aspects. Lab Invest 80, 617

13 Garnotel, R., Monboise, J. C., Randoux, A., Haye, B. and Borel, J. P. (1995) The Binding of Typi I Collagen to Lymphocyte Function-associated Antigen (LFA) 1 Integrin Triggers the Respiratory Burst of Human Polymorphonuclear Neutrophils. J Biol Chem 270, 27495-27505.

14 Werr, J., Johansson, J., Eriksson, E. E., Hedqvist, P., Ruoslahti, E. and Lindbom, L. (2000) Integrin $\alpha_{2} \beta_{1}$ (VLA-2) is a principal receptor used by neutrophils for locomotion in extravascular tissue. Blood 95, 1804-1809.

15 Bernheim, J., Rashid, G., Gavrieli, R., Korzets, Z. and Wolach, B. (2001) In vitro effect of advanced glycation end-products on human polymorphonuclear superoxide production. Eur J Clin Invest 31, 1064-1069.

16 Collison, K. S., Parhar, R. S., Saleh, S. S., Meyer, B. F., Kwaasi, A. A., Hammami, M. M., Schmidt, A. M., Stern, D. M. and Al-Mohanna, F. A. (2002) RAGE-mediated 
neutrophil dysfunction is evoked by advanced glycation end products (AGEs). J Leukoc Biol 71, 433-444.

17 Ming Li, Y., Tan, A. X. and Vlassara, H. (1995) Antibacterial activity of lysozyme and lactoferrin is inhibited by binding of advanced glycation-modified proteins to a conserved motif. Nat Med 1, 1057-1061.

18 Monboisse, J. C., Rittie, L., Lamfarraj, H., Garnotel, R. and Gillery, P. (2000) In vitro glycoxidation alters the interractions between collagens and human polymorphonuclear leucocytes. Biochem J 350, 777-783.

19 Schmidt, A. M., Yan, S. D., Brett, J., Mora, R., Nowygrod, R. and Stern, D. (1993) Regulation of Human Monocuclear Phagocyte Migration by Cell Surface-Binding Proteins for Advanced Glycation End Products. J Clin Invest 91, 2155-2168.

20 Sengoelge, G., Födinger, M., Skoupy, S., Ferrara, I., Zangerle, C., Rogy, M., Hörl, W. H., Sunder-Plassmann, G. and Menzel, J. (1998) Endothelial cell adhesion molecule and PMNL response to inflammatory stimuli and AGE-modified fibronectin. Kidney Int 54, 1637-1651.

21 Wong, R. K. M., Petit, A. I., Quinn, P. A., Jennings, S. C., Davies, J. E. and Ng, L. L. (2003) Advanced Glycation End Products Stimulate an Enhanced Neutrophil Respiratory Burst Mediated Through the Activation of Cytosolic Phospholipase A2 and Generation of Arachidonic Acid. Circulation 108, 1858-1864.

22 Wong, R. K., Pettit, A. I., Davies, J. E. and Ng, L. L. (2002) Augmentation of the neutrophil respiratory burst through the action of advanced glycation end products: a potential contributor to vascular oxidant stress. Diabetes 51, 2846-2853

23 Rieu, P., Porteu, F., Bessou, G., Lesavre, P. and Halbwachs-Mecarelli, L. (1992) Human neutrophils release their major membrane sialoprotein, leukosialin (CD43), during cell activation. Eur J Immunol 22, 3021-3026

24 Arcaro, A. and Wymann, M. P. (1993) Wortmannin is a potent phosphatidylinositol 3kinase inhibitor: the role of phosphatidylinositol 3,4,5-trisphosphate in neutrophil responses. Biochem J 296 (Pt 2), 297-301

25 Bouaouina, M., Blouin, E., Halbwachs-Mecarelli, L., Lesavre, P. and Rieu, P. (2004) TNF-induced beta2 integrin activation involves Src kinases and a redox-regulated activation of p38 MAPK. J Immunol 173, 1313-1320

26 DiMilla, P. A., Stone, J. A., Quinn, J. A., Albelda, S. M. and Lauffenburger, D. A. (1993) Maxima Migration of Human Smooth Muscle Cells on Fibronectin and Type IV Collagen Occurs at an Intermediate Attachment Strength. J Cell Biol 122, 729-737.

27 Mocsai, A., Zhou, M., Meng, F., Tybulewicz, V. and Lowell, C. (2002) Syk is required for integrin signaling in neutrophils. Immunity 16, 547-558

28 Anderson, S. I., Hotchin, N. A. and Nash, G. B. (2000) Role of the cytoskeleton in rapid activation of $\mathrm{CD} 11 \mathrm{~b} / \mathrm{CD} 18$ function and its subsequent downregulation in neutrophils. J Cell Sci 113, 2737-2745.

29 Kirstein, M., Brett, J., Radoff, S., Ogawa, S., Stern, D. and Vlassara, H. (1990) Advanced protein glycosylation induces trnsendothelial human monocyte chemotaxis and secretion of platelet-derived growth factor: role in vascular disease of diabetes and aging. Proc Natl Acad Sci USA 87, 9010-9014

30 Miyata, T., Inagi, R., Lida, Y., Sato, M., Yamada, N., Oda, O., Maeda, K. and Seo, H. (1994) Involvement of $\beta_{2}$-microglobulin modified with advanced glycation end products in the pathogenesis of hemodialysis_associated amyloidosis. J Clin Invest 93, 521-528

31 Yeh, C. H., Sturgis, L., Haidacher, J., Zhang, X. N., Sherwood, S. J., Bjercke, R. J., Juhasz, O., Crow, M. T., Tilton, R. G. and Denner, L. (2001) Requirement for p38 and 
p44/p42 mitogen-activated protein kinases in RAGE-mediated nuclear factor-kappaB transcriptional activation and cytokine secretion. Diabetes 50, 1495-1504

32 Lander, H. M., Tauras, J. M., Ogiste, J. S., Hori, O., Moss, R. A. and Schmidt, A. M. (1997) Activation of the receptor for advanced glycation end products triggers a p21(ras)-dependent mitogen-activated protein kinase pathway regulated by oxidant stress. J Biol Chem 272, 17810-17814

33 Yan, S. D., Schmidt, A. M., Anderson, G. M., Zhang, J., Brett, J., Zou, Y. S., Pinsky, D. and Stern, D. (1994) Enhanced cellular oxidant stress by the interaction of advanced glycation end products with their receptors/binding proteins. J Biol Chem 269, 9889-9897

34 Huttunen, H. J., Fages, C. and Rauvala, H. (1999) Receptor for advanced glycation end products (RAGE)-mediated neurite outgrowth and activation of NF-kappaB require the cytoplasmic domain of the receptor but different downstream signaling pathways. J Biol Chem 274, 19919-19924

35 Vincent, A. M., Perrone, L., Sullivan, K. A., Backus, C., Sastry, A. M., Lastoskie, C. and Feldman, E. L. (2007) Receptor for advanced glycation end products activation injures primary sensory neurons via oxidative stress. Endocrinology 148, 548-558

36 Armulik, A., Velling, T. and Johansson, S. (2004) The integrin $\beta 1$ subunit transmembrane domain regulates phosphatidylinositol 3-kinase-dependent tyrosine phosphorylation of Crk-associated substrate. Mol Cell Biol 15, 2558-2567

37 Axelsson, L., Hellberg, C., Melander, F., Smith, D., Zheng, L. and Andersson, T. (2000) Clustering of $\beta 2$-integrins on human neutrophils activates dual signaling pathways to Ptdlns 3-kinase. Exp Cell Res 256, 257-263

38 Löfgren, R., Ng-Sikorski, J., Sjölander, A. and Andersson, T. (1993) $\beta_{2}$ Integrin Engagement Triggers Actin Polymerization and Phosphatidylinositol TrisphosphateFormation in Non-adherent Human Neutrophils. J Cell Biol 123, 15971605.

39 Hannigan, M., Zhan, L., Li, Z., Ai, Y., Wu, D. and Huang, C.-K. (2002) Neutrophils lacking phosphoinositide 3-kinase $\gamma$ show loss of directionality during $N$-formyl-MetLeu-Phe-induced chemotaxis. Proc Nat1 Acad Sci 99, 3603-3608.

40 Heit, B., Tavener, S., Raharjo, E. and Kubes, P. (2002) An intracellular signaling hierarchy determines direction of migration in opposing chemotactic gradients. J Cell Biol

159, 91-102.

41 Sadhu, C., Masinovsky, B., KDick, K., Sowell, C. G. and Staunton, D. E. (2003) Essential Role of Phosphoinositide 3-Kinase $\delta$ in Neutrophil Directional Movement. J Immunol 170, 2647-2654.

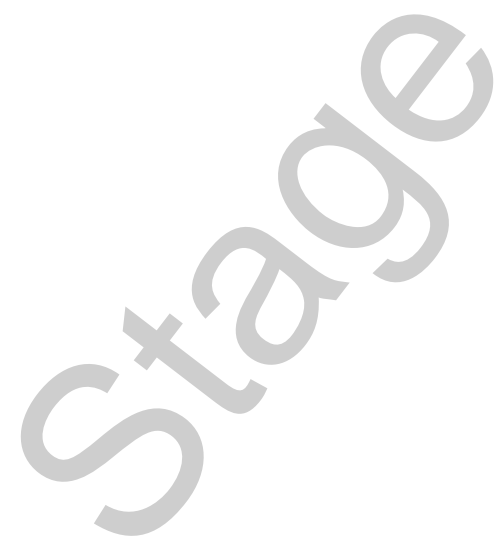




\section{FIGURE LEGENDS}

\section{Figure 1: Adhesion of stimulated neutrophils to AGE-Collagen}

Adhesion of f-MLP-activated neutrophils to AGE-collagen was tested with and without presence of inhibitors. Adhesion of f-MLP-activated neutrophils to AGE-collagen was significantly increased compared to control collagen. Wortmanin (10nM) and anti-RAGE antibodies inhibit adhesion of f-MLP-stimulated neutrophils to AGE-Collagen (respectively $* * \mathrm{p}<0.01$ and $* * * \mathrm{p}<0.001)$. In contrast, inhibition of the MAPK/ERK pathway with PD98059 $(40 \mu \mathrm{M})$ or MAPK/P38 with SB203580 $(10 \mu \mathrm{M})$ had no effect. Results are expressed as mean $\pm \mathrm{SD}$ of 3 independent experiments.

\section{Figure 2: Adhesion of resting neutrophils to AGE-collagen}

Resting neutrophils were allowed to adhere to control collagen or AGE-collagen coated wells. Adhesion of resting neutrophils to AGE-collagen was significantly increased compared to control collagen $(* p<0,05)$. Adhesion of resting neutrophils to AGE-collagen was significantly inhibited by preincubation with anti-RAGE antibody $(70 \mu \mathrm{g} / \mathrm{ml})$ or wortmanin $(10 \mathrm{nM})(* * \mathrm{p}<0.01)$. Results are expressed as a percentage of adhesion in absence of inhibitors (buffer) and mean \pm SD of 3 independent experiments. Each experiment was performed in triplicate.

\section{Figure 3: Activation of PI3-Kinase on AGE-collagen}

Resting neutrophils, $10 \times 10^{6}$ for each condition, were incubated in the presence of $\mathrm{Ca}^{++}$and $\mathrm{Mg}^{++}$with AGE collagen or control collagen for 30 minutes. Cell lysates were then used for immunoprecipitation of phospho-tyrosine proteins and in vitro formation of radio-labelled phosphatidyl inositol phosphate (PIP). $\mathrm{P}^{32}$ labelled lipids were then separated by chromatography on a silica plaque. PI3 kinase activity is related to the amount of PIP formed. 
AGE-Collagen greatly enhanced PIP formation of resting neutrophils compared to control collagen.

Figure 4: Morphological changes of f-MLP-stimulated neutrophils on collagen coated surface.

A/ Neutrophils were analysed on an inverted microscope 30 min after stimulation with $10^{-8} \mathrm{M}$ f-MLP and after fixation with formaldehyde and staining of polymerized actin with phalloidin. f-MLP-activated neutrophils on control collagen have a migratory phenotype: cells are polarized with cytoplasmic expansions corresponding to pseudopod and uropod, and accumulation of polymerized actin in the pseudopod. On AGE-collagen, f-MLP activated neutrophils undergo a marked spreading; they are more flatteed than on control collagen. Actin polymerization is diffuse. B/ Cellular area was determined by manually tracing the cell perimeter in the digital image. Results are representative of $75 \%$ of the cells from more than 3 independent experiments. Cell surface of f-MLP-activated neutrophils is increased on AGEcollagen compared to control collagen but not statistically significant $(\mathrm{p}=0.08)$.

\section{Figure 5: Neutrophil migration on AGE-collagen}

A/ Neutrophil chemotaxis on control collagen or AGE-collagen coated surfaces in response to a chemotactic gradient (Zymosan) was measured in an under agarose assay. Directed migration in response to zymosan was measured after 2.5 hours incubation at $37^{\circ} \mathrm{C}$ with $\mathrm{CO}_{2}$. Migration in response to a chemotactic gradient is significantly decreased on AGE-Collagen $(10.6 \pm 7.8 \mathrm{~mm})$ compared to control collagen $(34.4 \pm 6.8 \mathrm{~mm})(* * * \mathrm{p}<0.001)$. Results are expressed as mean $\pm \mathrm{SD}$ of 3 independent experiments, each performed in 6 replicates. $\mathbf{B} /$ Neutrophil chemokinesis was recorded by time-lapse video microscopy. Neutrophil spontaneous migration rate is slightly increased on AGE-collagen $(6.7 \pm 1.36 \mu \mathrm{m} / \mathrm{min})$ 
compared to native collagen $(5.57 \pm 0.8 \mu \mathrm{m} / \mathrm{min})$ but not statiscally significant. Stimulation with f-MLP $\left(10^{-8} \mathrm{M}\right)$ significantly increases neutrophil random migration rate (chemokinesis) on native collagen $\left(11.6 \pm 1.9 \mu \mathrm{m} / \mathrm{min},{ }^{* * *} \mathrm{p}<0.001\right)$ but not on AGE-collagen $(8.2 \pm 0.4$ $\mu \mathrm{m} / \mathrm{min}$, NS, No significance). Results are expressed as mean \pm SD of 9 independent experiments.

\section{Figure 6: Role of RAGE on neutrophil migration on AGE-collagen}

Effect of RAGE inhibition on neutrophils chemokinesis was studied by time lapse videomicroscopy. A/ Neutrophils were preincubated with anti-RAGE Fab'2 or control Fab'2 $(200 \mu \mathrm{g} / \mathrm{ml})$, and allowed to migrate on AGE-Collagen after stimulation with f-MLP. RAGE inhibition with anti-RAGE (Fab')2 leads to a significant increase in f-MLP induced migration of neutrophils on AGE-Collagen $(* * p \leq 0,01)$ whereas control Fab'2 had no effect. B/ The same experiment was conducted on Control-Collagen. RAGE inhibition with anti-RAGE (Fab')2 does not modify neutrophil migration on Control-Collagen. Results are expressed as mean $\pm \mathrm{SD}$ of 3 independent experiments.

Figure 7: Effect of PI3-Kinase inhibition on f-MLP-induced neutrophil migration on AGE-collagen.

Neutrophils were allowed to migrate on control collagen or AGE-collagen coated surfaces. $f$ MLP-induced chemotaxis was studied in the presence PI3-Kinase inhibitors (10nM

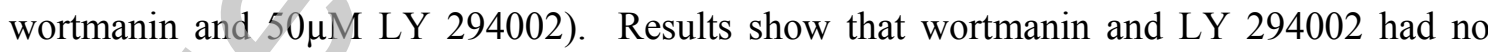
effect on neutrophil migration on control collagen (NS, no significance); whereas they significantly enhanced neutrophil migration on AGE-collagen $(* * * p<0.001)$. Results are expressed as mean of 3 independent experiments. 


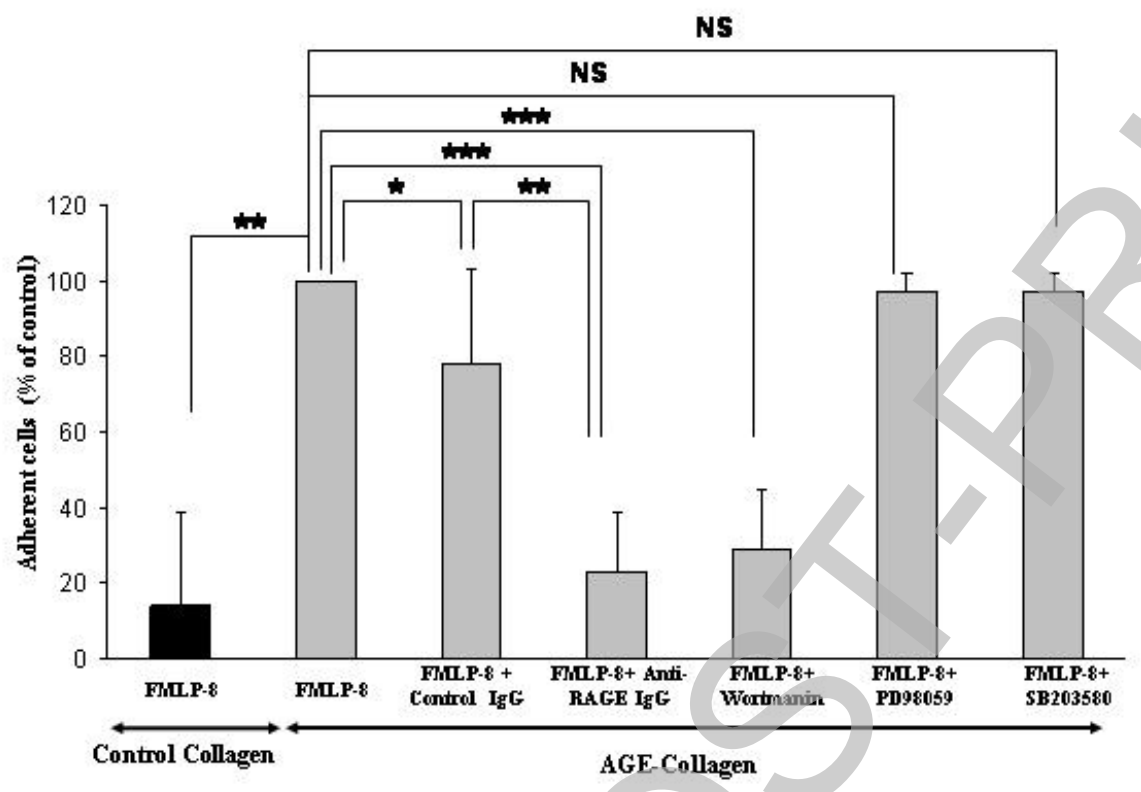

Figure 1 


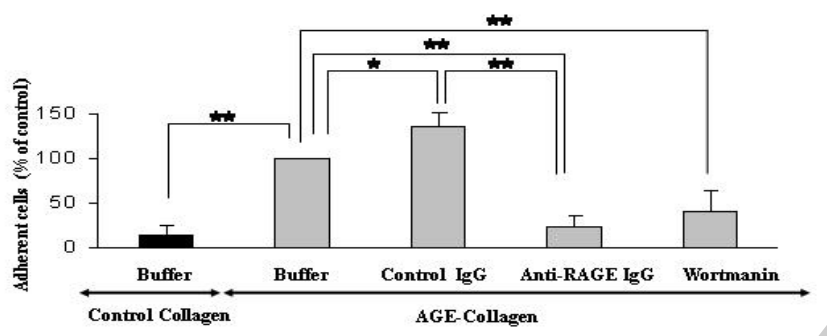

\section{Figure 2}

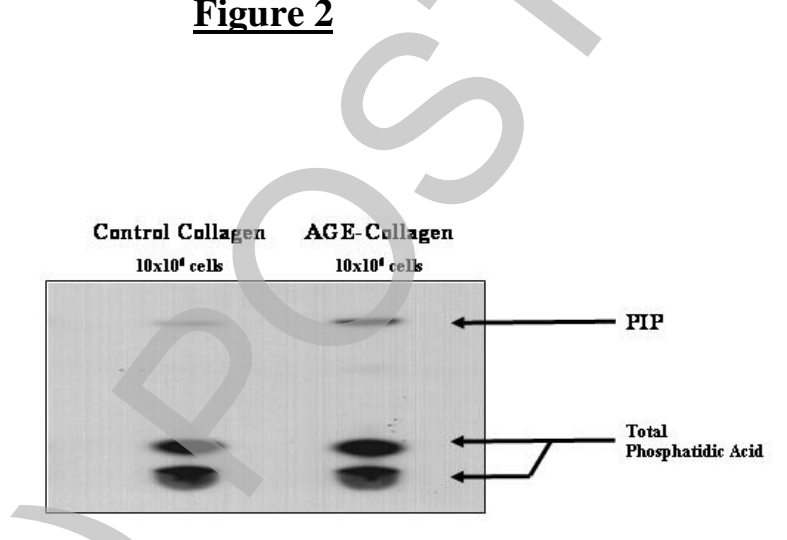

$\underline{\text { Figure } 3}$ 
$\mathbf{A}$

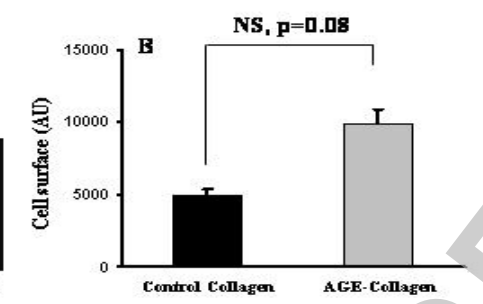

Figure 4
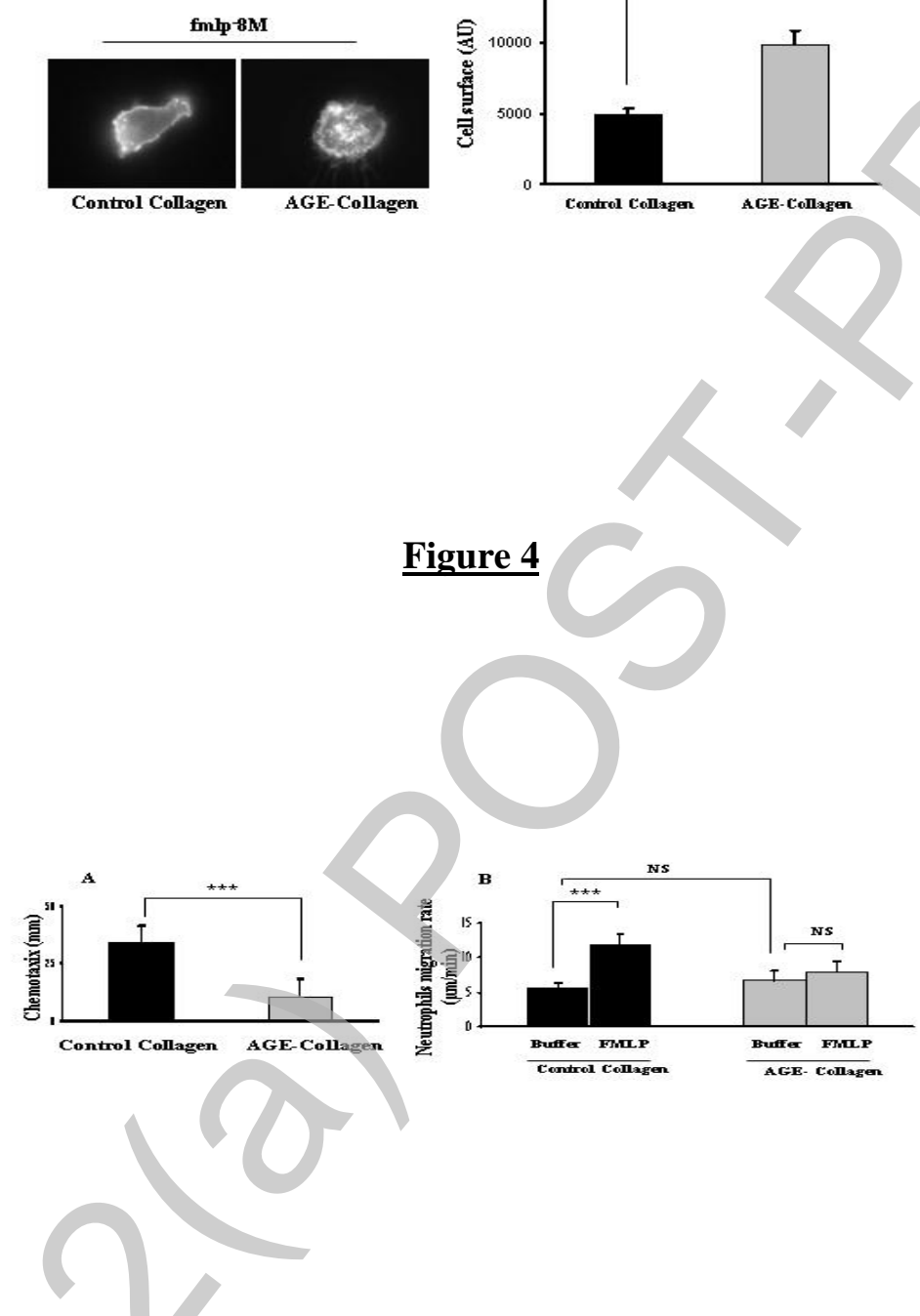

Control Collagen AGE-Collagen

\section{Figure 5}




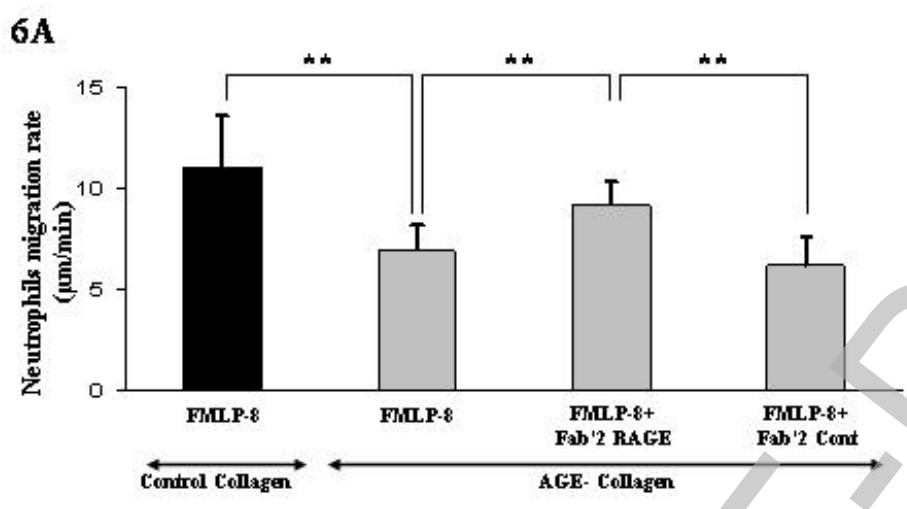

$6 B$

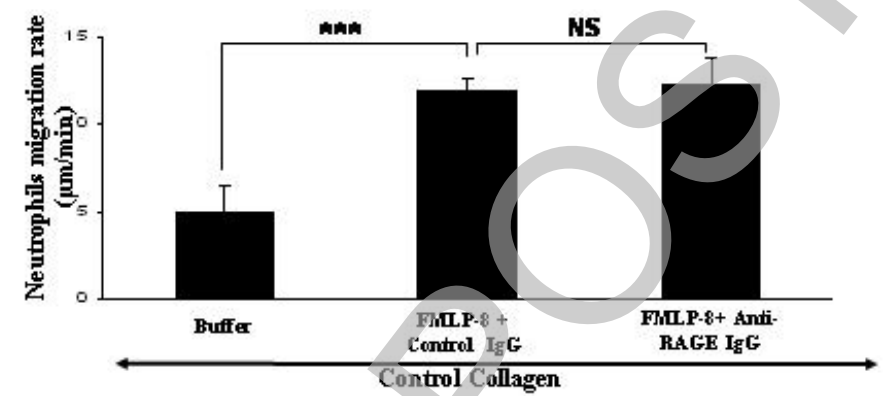

Figure 6 


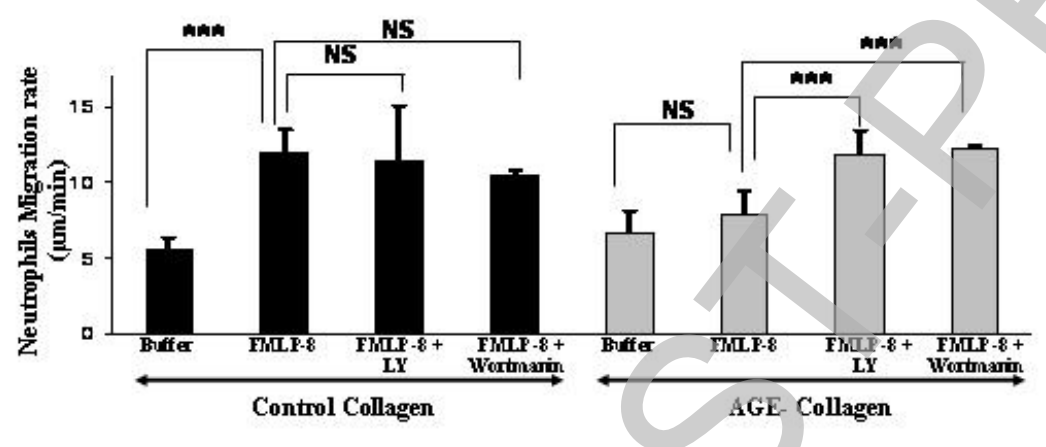

Figure 7 